\title{
Validity and reliability of inertial sensors for elbow and wrist range of motion assessment
}

\author{
Vanina Costa ${ }^{\text {Corresp., } 1,2}{ }^{2}$ Óscar Ramírez ${ }^{2}$, Abraham Otero ${ }^{1}$, Daniel Muñoz-García ${ }^{3}$, Sandra Uribarri ${ }^{4}$, Rafael Raya ${ }^{1,2}$ \\ 1 Department of Information Systems Engineering, Polytechnic School, University San Pablo CEU, Madrid, Spain \\ 2 Werium Assistive Solutions Ltd., Madrid, Spain \\ 3 Motion in Brains Research Group, Neuroscience and Motion Science Institute, The Center for Advanced Studies University La Salle (Universidad \\ Autónoma de Madrid), Madrid, Spain \\ 4 The Center for Advanced Studies University La Salle, Universidad Autónoma de Madrid, Madrid, Spain \\ Corresponding Author: Vanina Costa \\ Email address: vanina.costacortez@ceu.es
}

Background. Elbow and wrist chronic conditions are very common among musculoskeletal problems. These painful conditions affect muscle function, which ultimately leads to a decrease in the joint's Range Of Motion (ROM). Due to their portability and ease of use, goniometers are still the most widespread tool for measuring ROM. Inertial sensors are emerging as a digital, low-cost and accurate alternative.

However, whereas inertial sensors are commonly used in research studies, due to the lack of information about their validity and reliability, they are not widely used in the clinical practice. The goal of this study is to assess the validity and intra-inter-rater reliability of inertial sensors for measuring active ROM of the elbow and wrist.

Materials and methods. Measures were taken simultaneously with inertial sensors (Werium ${ }^{\mathrm{TM}}$ system) $^{\mathrm{T}}$ and a universal goniometer. The process involved two physiotherapists ("rater A" and "rater B") and an engineer responsible for the technical issues. 29 asymptomatic subjects were assessed individually in two sessions separated by 48 hours. The procedure was repeated by rater A followed by rater B with random order. Three repetitions of each active movement (elbow flexion, pronation, and supination; and wrist flexion, extension, radial deviation, and ulnar deviation) were executed starting from the neutral position until the ROM end-feel; i.e., until ROM reached its maximum due to be stopped by the anatomy. The coefficient of determination $\left(r^{2}\right)$ and the Intraclass Correlation Coefficient (ICC) were calculated to assess the intra-rater and inter-rater reliability. The Standard Error of the Measurement (SEM) and the Minimum Detectable Change (MDC) and a Bland-Altman plots were also calculated.

Results. Similar ROM values when measured with both instruments were obtained for the elbow (maximum difference of $3^{\circ}$ for all the movements) and wrist (maximum difference of $1^{\circ}$ for all the movements). These values were within the normal range when compared to literature studies. The concurrent validity analysis for all the movements yielded ICC values $\geq 0.78$ for the elbow and $\geq 0.95$ for the wrist. Concerning reliability, the ICC values denoted a high reliability of inertial sensors for all the different movements. In the case of the elbow, intra-rater and inter-rater reliability ICC values range from 0.83 to 0.96 and from 0.94 to 0.97 , respectively. Intra-rater analysis of the wrist yielded ICC values between 0.81 and 0.93 , while the ICC values for the inter-rater analysis range from 0.93 to 0.99 .

Conclusions. Inertial sensors are a valid and reliable tool for measuring elbow and wrist active ROM. Particularly noteworthy is their high inter-rater reliability, often questioned in measurement tools. The lowest reliability is observed in elbow prono-supination, probably due to skin artefacts. Based on these results and their advantases inertial sensors can be considered a valid assessment tool for wrist and 
elbow ROM.

Peer] reviewing PDF | (2020:02:46039:1:1:NEW 18 Jun 2020) 
2 Validity and reliability of inertial sensors for elbow and 3 wrist range of motion assessment

4

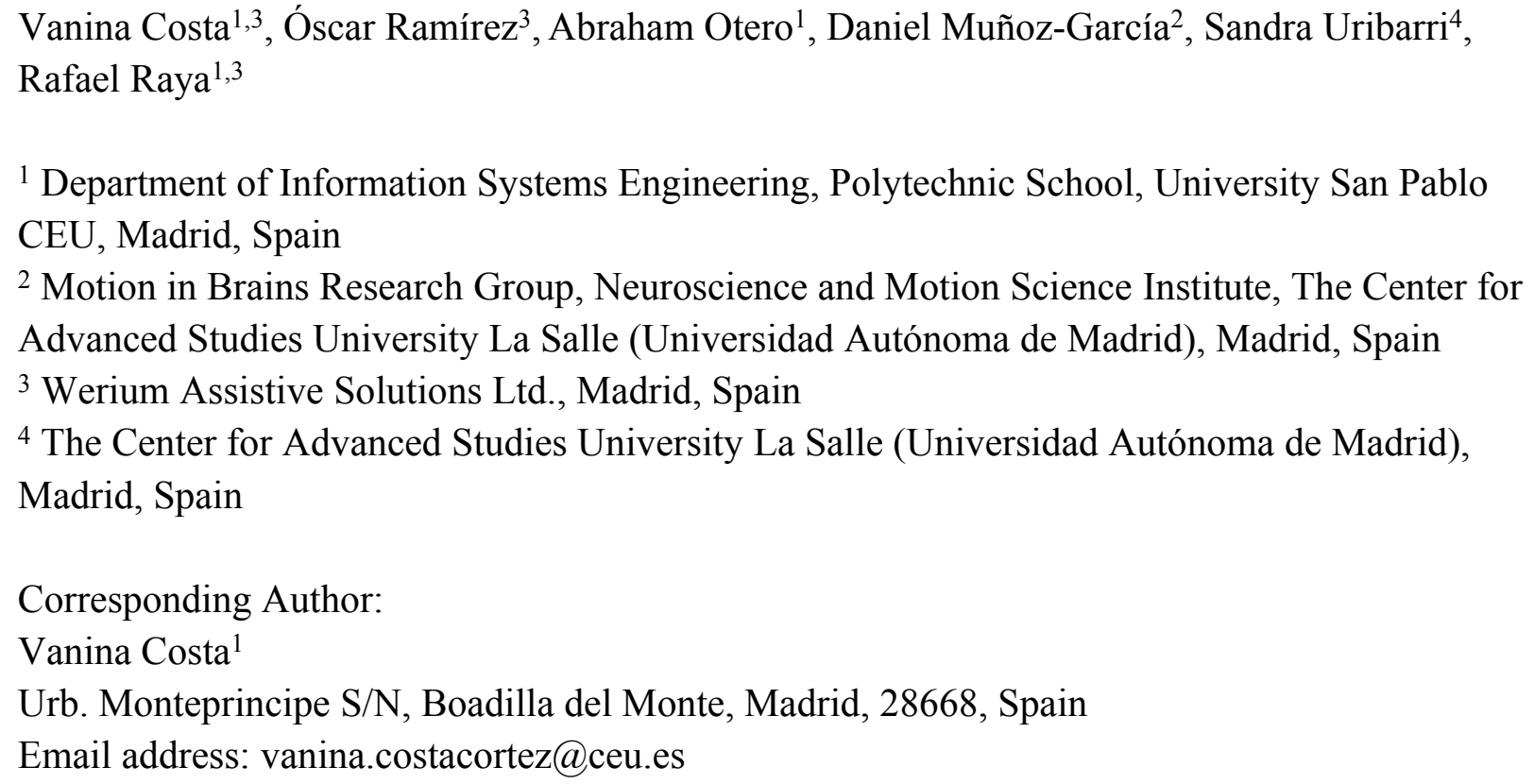

\section{Abstract}

Background. Elbow and wrist chronic conditions are very common among musculoskeletal problems. These painful conditions affect muscle function, which ultimately leads to a decrease in the joint's Range Of Motion (ROM). Due to their portability and ease of use, goniometers are still the most widespread tool for measuring ROM. Inertial sensors are emerging as a digital, low-cost and accurate alternative. However, whereas inertial sensors are commonly used in research studies, due to the lack of information about their validity and reliability, they are not widely used in the clinical practice. The goal of this study is to assess the validity and intra-interrater reliability of inertial sensors for measuring active ROM of the elbow and wrist.

Materials and methods. Measures were taken simultaneously with inertial sensors (Werium ${ }^{\mathrm{TM}}$ system) and a universal goniometer. The process involved two physiotherapists ("rater A" and "rater B") and an engineer responsible for the technical issues. 29 asymptomatic subjects were assessed individually in two sessions separated by 48 hours. The procedure was repeated by rater A followed by rater B with random order. Three repetitions of each active movement (elbow flexion, pronation, and supination; and wrist flexion, extension, radial deviation, and ulnar deviation) were executed starting from the neutral position until the ROM end-feel; i.e., until ROM reached its maximum due to be stopped by the anatomy. The coefficient of determination 
$40 \quad\left(\mathrm{r}^{2}\right)$ and the Intraclass Correlation Coefficient (ICC) were calculated to assess the intra-rater and 41 inter-rater reliability. The Standard Error of the Measurement (SEM) and the Minimum 42 Detectable Change (MDC) and a Bland-Altman plots were also calculated.

43 Results. Similar ROM values when measured with both instruments were obtained for the elbow 44 (maximum difference of $3^{\circ}$ for all the movements) and wrist (maximum difference of $1^{\circ}$ for all 45 the movements). These values were within the normal range when compared to literature studies. 46 The concurrent validity analysis for all the movements yielded ICC values $\geq 0.78$ for the elbow 47 and $\geq 0.95$ for the wrist. Concerning reliability, the ICC values denoted a high reliability of 48 inertial sensors for all the different movements. In the case of the elbow, intra-rater and inter49 rater reliability ICC values range from 0.83 to 0.96 and from 0.94 to 0.97 , respectively. Intra50 rater analysis of the wrist yielded ICC values between 0.81 and 0.93 , while the ICC values for 51 the inter-rater analysis range from 0.93 to 0.99 .

52 Conclusions. Inertial sensors are a valid and reliable tool for measuring elbow and wrist active measurement tools. The lowest reliability is observed in elbow prono-supination, probably due to skin artefacts. Based on these results and their advantages, inertial sensors can be considered a valid assessment tool for wrist and elbow ROM.

\section{Introduction}

Human motion capture has many applications in fields such as automotive industry, 3D animation, sports, activities of daily living and physiotherapy (Ahmad et al., 2013). In the medical field, human movement is mainly important for the diagnosis of neuro-motor disorders and follow-up on physical training or therapy interventions. Musculoskeletal disorders are a diversified group of conditions that affect the normal function of the skeletal system. They comprise an extensive range of conditions; some of them are acute and short-lived, while others result in progressive deterioration and disability. Between $20 \%-33 \%$ of the world's population suffers from some painful musculoskeletal condition (GBD 2017 Disease and Injury Incidence and Prevalence Collaborators et al., 2018). Joints involved suffer from pain, diminished ROM and physical impairment. This situation leads to mobility and functional limitations, preventing the subject from performing daily activities normally.

Although kinematic parameters such as acceleration or velocity can play a role in evaluating the patient's motor control or functional assessment, the most common parameter used in the clinical practice to characterize the human joint is the range of motion (ROM). The purpose of this paper is to study the validity of inertial sensors to measure the elbow and wrist active ROM. Elbow and wrist chronic conditions are very common among musculoskeletal problems. However, the measure of the kinematic of the upper limb can be complex due to the multiple degrees of freedom of their joints. 
79 Both for upper and lower limb, the goniometer is the simplest and most extended tool for 80 measuring ROM in the clinical practice (Vauclair et al., 2018). It was developed approximately

8160 years ago, and its versatility and usability led to this instrument being promptly integrated into 82 the field of physiotherapy and rehabilitation as a helpful evaluation tool (Gajdosik \& Bohannon, 83 1987; Roach et al., 2013). However, some authors question the poor intertester reliability of the 84 universal goniometer. Chapleau et al. have assessed its validity compared with radiographic 85 measurements. They measured ROM in flexion, extension and carrying angle of the elbow using 86 three repetitions for each movement. The intraclass correlation coefficients (ICC) ranged from 870.94 to 0.97 from the goniometric measurements and from 0.98 to 0.99 for the radiographic 88 measurements (Chapleau et al., 2011). Despite the high ICC, the authors reported maximal 89 errors of $10^{\circ}$ when the ROM was measured using the goniometer $\left(10.3^{\circ}\right.$ for extension, $7.0^{\circ}$ for 90 flexion, and $6.5^{\circ}$ for carrying angle). Clinicians also report drawbacks such as the need for 91 holding manually the arms of the goniometer while taking a measurement, the stabilization of 92 these during the readout, and the experience required to locate landmarks in the patient's body 93 (Roach et al., 2013; Mehta et al., 2017).

94
The evolution of the universal goniometer is its digital version, often called inclinometer. Kolber et al. studied the reliability of the goniometer and the digital inclinometer to measure shoulder flexion, abduction, internal and external rotation. Two physiotherapists participated in the study. Results showed an excellent ICC for goniometry $(>0.94)$ and digital inclinometer $(>0.95)$ between the two examiners (Kolber et al., 2012).

Technological advances in medical instrumentation have enabled more precise and specific motion capture systems that provide a more complete and objective characterization of the patient's mobility. Photogrammetric and inertial systems are the most advanced technologies in the field of biomechanics, (Yahya et al., 2019). Besides the range of motion, they can provide useful information such as velocity, acceleration and other derived kinematic and dynamic parameters. Photogrammetric systems, also called optical-tracking systems (Vicon ${ }^{\mathrm{TM}}$, Qualysis $^{\mathrm{TM}}$, OptiTrack ${ }^{\mathrm{TM}}$, etc.), are considered the gold standard for ROM measurement. However, they have drawbacks such as high economical and computational cost, marker occlusion, the requirement of an instrumented environment, and time-consuming setups, which prevent their usage in clinical practice (Tsushima, Morris \& McGinley, 2003; Mehta et al., 2017).

The evolution of microsensors has given rise to a new miniatured generation of Inertial Measurement Units (IMUs) based on micro-electro-mechanical systems. These devices can be successfully used for accurate, non-invasive and portable motion tracking (Filippeschi et al., 2017). IMUs or inertial sensors are traditionally comprised of accelerometers and gyroscopes. An accelerometer contains a mass suspended by a spring and placed in some housing. Changes in the mass displacement caused by movement are related directly with changes in acceleration. 
119 A gyroscope measures the angular velocity by using vibration to determine the orientation. When

120

121

122

123

124

125

126

127

128

129

130

131

132

133

134

135

136

137

138

139

140

141

142

143

144

145

146

147

148

149

150

151

152

153

154

155

156

157

a magnetometer is integrated, they are also named magneto-inertial sensors.

Inertial sensors-based systems are becoming very precise. Additionally, their relative affordability respect to optical-tracking systems, the faster and simpler setups, and the advantage of not being confined to a laboratory setting, make them ideal tools for assessing ROM in the clinical practice (Ahmad et al., 2013). There are several reviews which explore the usage of these instruments for a variety of health purposes, yielding interesting research in biomechanics, such as the classification of age-related kinematic impairment (Greene et al., 2015; Roldán-Jiménez \& Cuesta-Vargas, 2016), body mobility assessment (Iwasaki \& Hirotomi, 2015), gait analysis and development of athletes' performance (Camomilla et al., 2018) and sports (Boddy et al., 2019; Wells et al., 2019).

In the context of neuromotor disorders, its usefulness has been proved even in the most serious motor dysfunctions, such as is the case of neurological motor disorders (Iwasaki \& Hirotomi, 2015; Raya et al., 2015), paraplegic limbs (Wiesener et al., 2019) or osteoarthritis (Chen et al., 2015). Cerebral palsy, stroke, traumatic brain injury, and motor neuron disease are some of the conditions where the use of inertial sensors in rehabilitation therapies has proven to be beneficial (Bai et al., 2015; Bertomeu-Motos et al., 2015). They also play a promising role in quantifying patients' ROM and daily living activities such as reaching and grasping (Ertzgaard et al., 2016). And there are promising results testing their validity and reliability to assess the ROM of the cervical joint in subjects with CP (Carmona-Pérez et al., 2020).

Concerning the upper limb biomechanics, there are several studies testing the validity of inertial sensors. Robert-Lachaine et al. (Robert-Lachaine et al., 2017) conducted a validation of an inertial system (Xsens ${ }^{\mathrm{TM}}$ ) compared to an optoelectronic system (OptoTrak ${ }^{\mathrm{TM}}$ ). They studied the whole-body kinematics from 12 participants performing some functional movements (elbow flexion/extension and pronation/supination and wrist flexion/extension, lateral deviation and circumduction). Although in general they observed acceptable results, they reported the largest errors for the elbow and shoulder, and they attributed them to the different biomechanical models more than to the technological precision. They concluded that caution should be taken for comparison involving IMUs and optoelectronic systems.

Ertzgaard et al. studied a set of coordination tasks comparing an inertial sensing system with an optical tracking system. Results showed small systematic errors in all the studied movement planes ranging between $1.2^{\circ}$ and $1.3^{\circ}$. The lowest intraclass correlations coefficients were obtained for elbow prono-supination (Ertzgaard et al., 2016). Sacco et al. used an inertial sensing system to measure the upper limb ROM in seventy-seven elderly patients. In this case, authors concluded that the system seemed less reliable and valuable compared to the traditional methods

Peer) reviewing PDF | (2020:02:46039:1:1:NEW 18 Jun 2020) 
158

159

160

161

162

163

164

165

166

167

168

169

170

171

172

173

174

175

176

177

178

179

180

181

182

183

184

185

186

187

188

189

190

191

192

193

194

195

196

197

used in gerontology, but not significant differences were found between planes of movement (Sacco et al., 2015).

There are a few studies analyzing the validity of inertial sensing systems of elbow and wrist ROM for each plane of movement, but most of these studies have usually been carried out under lab conditions (Muller et al., 2017; Robert-Lachaine et al., 2017). Some of them are preliminary studies without a statistical sample size (Wells et al., 2015). Others do not conduct a study of validity and reliability of the inertial sensors' measurements with the goniometer's (Tian et al., 2015; Zhou et al., 2008; Zhang, Wong \& Wu, 2011), something essential to test whether it is possible to replace the goniometer with this new technology. There is also a lack of standardized protocols for motion analysis other than for gait because most of the studies were conducted under lab conditions. The transition from a research instrument to a clinical reliable tool is one of the main challenges concerning inertial sensing systems and the evaluation of upper limb function (Ertzgaard et al., 2016).

There also are studies that focus on the usage of smartphones, that integrate inertial sensors, for ROM measurement. They are an easy-to-use and accessible tool, making them practical in clinical assessments. While some studies describe a high reliability between universal goniometer and smartphones assessment, others reflect a large heterogeneity when analyzing each movement separately. Behnoush et al. obtained a good validity measure for a smartphone compared with a goniometer when used to measure elbow supination ( $\mathrm{ICC}=0.92)$, but more disappointing results were obtained when used to measure elbow flexion (ICC $=0.73$ ) (Behnoush et al., 2016). This study addressed only the validity of the measures, and not their inter-rater and intra-rater reliability. Furthermore, the measurements carried out with the goniometer were not performed by trained physiotherapists who routinely use this device at work, but by doctors who received training on how to use the goniometer to carry out the experiment. In other similar study, Vauclair et al. stated that the smartphone app (Clinometer ${ }^{\mathrm{TM}}$ ) overestimated flexion (mean $\left.6.4^{\circ}+-1.0^{\circ}\right)$ and supination $\left(5.9^{\circ}+-1.9^{\circ}\right)$ respect to the universal goniometer. However, there was not a significant difference in pronation (Vauclair et al., 2018).

The goal of this paper is to validate inertial sensors for elbow and wrist active ROM measurement. We shall analyze their validity when compared with the measurements taken by physiotherapists using a goniometer, as well as their intra-rater and inter-rater reliability. For that purpose, the Werium ${ }^{\mathrm{TM}}$ motion capture system was employed. It is based on inertial technology; more specifically on ENLAZA ${ }^{\mathrm{TM}}$ inertial sensor (Raya et al., 2012). This device has already proven to be an accurate solution for cervical ROM measurement (Raya et al., 2018). However, the validity and reliability of this system on other joints, specifically elbow and wrist, had not been previously studied.

\section{Materials \& Methods}

Study design

Peer] reviewing PDF | (2020:02:46039:1:1:NEW 18 Jun 2020) 
198

199

200

201

202

203

204

205

206

207

208

209

210

211

212

213

214

215

216

217

218

219

220

221

222

223

224

225

226

227

228

229

230

231

232

233

234

235

236

237

This study was designed to assess criterion-related validity and intra-inter-rater reliability of ROM measures for the wrist and elbow. Criterion-related validity is related to the capability of one instrument to deliver results as close as possible to the gold standard to which it is being compared. Reliability aims to measure consistency between repeated measurements of the same variable on the same individual, who is subjected to the same conditions. While intra-rater reliability deals with the consistency of one individual evaluating the same fact on two different occasions, inter-rater reliability focuses on measuring the variability of two or more raters evaluating the same fact on the same occasion.

The clinical validation was performed in the Center for Advanced Studies University La Salle (IRF La Salle, Madrid, Spain), which granted ethical approval (cseuls-pi-146/2017). Written consent was obtained from the patients to carry out the study. Two physiotherapists (raters " $\mathrm{A}$ " and "B") were responsible for interacting with the patient and taking readings from the goniometer, as well as placing the inertial sensors on the patient's body. Additionally, a technician was responsible for taking measurements from the inertial sensors by means of a personal computer, as well as typing in a template both the measurements from the inertial sensors and the measurements provided by the physiotherapists from the goniometer. All the subjects were individually evaluated in two successive sessions with an interval of 48 hours. They performed the distinctive movements of each joint in an active way. Both sensors and goniometer were placed simultaneously; in this way, it was guaranteed that both devices were measuring the same movement. This process was repeated by rater A followed by rater B in random order. The complete description of the study, which is explained below, was performed identically for both elbow and wrist.

\section{Participants}

Participants were recruited by the IRF La Salle. Inclusion criteria included men and women between the age of 20 and 40 with approximately normal body mass index $\left(<25 \mathrm{~kg} / \mathrm{m}^{2}\right)$, and without any joint pain. Exclusion criteria were pregnancy, history of joint pain either during the last 8 months or during data collection, and noticeable deformity of the target joint. A total of 29 asymptomatic adults participated in the study. 20 of them were men, with an average age of $24.10 \pm 3.86$, height of $1.79 \pm 0.08 \mathrm{~m}$, weight of $76.19 \pm 12.71 \mathrm{~kg}$, and body mass index of 23.67 $\pm 3.19 \mathrm{~kg} / \mathrm{m}^{2}$. The remaining 9 were women with an average age of $21.33 \pm 1.50$, height of 1.62 $\pm 0.09 \mathrm{~m}$, weight of $58.78 \pm 9.65 \mathrm{~kg}$, and body mass index of $22.16 \pm 1.77 \mathrm{~kg} / \mathrm{m}^{2}$. Table 1 presents the subjects' demographic information.

\section{Data collection instruments}

Measures were taken by the Winkelmesser ${ }^{\mathrm{TM}}$ plastic goniometer manufactured by Kirchner \& Wilhelm GmbH \& Co. with $1^{\circ}$ increments, and by the Werium ${ }^{\mathrm{TM}}$ motion capture system (Fig. 1). This system consists of two inertial sensors; one must be placed in the distal part of the extremity (moving sensor) and the other in the proximal part (fixed sensor). These sensors have an 
238 accuracy of $\pm 1^{\circ}$ (Raya et al., 2018). The angle measured will be the relative angle between both 239 sensors. By placing a sensor in the proximal part of the extremity the possible compensatory 240 movements of the patient are ignored when performing the measurement with the inertial 241 sensors.

242

243 The software Pro Motion Capture ${ }^{\mathrm{TM}}$ was used to take the ROM measures and to visualize these 244 data in real-time (Fig. 2). The measurements of both inertial sensors are sent via Bluetooth to the 245 PC where the data acquisition software is running, and from the measurements of both sensors, 246 the software calculates the ROM of the joint. A specific template was created to support the 247 process of data gathering. The random order in which raters had to assess participants in each 248 session was generated by the statistical software GraphPad.

\section{Procedure}

Before start taking measurements, the subject's sex, age, height, and weight were registered.

Then, the subject was asked about his/her dominant arm, for elbow and wrist evaluation. The two raters inspected the joint and agreed on the anatomic landmarks in which the goniometer and sensors should be placed. The subject's skin was marked with eyeliner when necessary to facilitate the recognition of these landmarks (Fig. 3). The goniometer was placed following bibliographic guidelines for an ordinary ROM assessment of elbow and wrist (Norkin \& White, 2009).

In the case of the elbow, the moving sensor was placed on the posterior part of the forearm $2 \mathrm{~cm}$ cranial from the radial and ulnar styloid. The fixed sensor was positioned at the lateral line of the arm (between the acromion and the lateral epicondyle of the elbow). Elbow assessment involved flexion and pronation-supination movements. Concerning the wrist, the moving sensor was placed in the middle of the posterior side of the hand (above the metacarpals). The fixed sensor was placed on the posterior part of the forearm $2 \mathrm{~cm}$ cranial from the radial and ulnar styloid. Flexion-extension and radial-ulnar deviation were the distinctive movements in the wrist. Both goniometer and inertial sensors were placed preserving the free active mobility of the subject, without any interference with the movements.

The examiner explained and performed the movement for the subject, familiarizing the participant with the activity. Regarding elbow flexion, the neutral position was standing upright in an anatomical position with the palms of the hands extended facing forward and the arms facing the sides of the body. During the flexion movement, the subject flexed the elbow by directing the palm of his/her hand towards the shoulder to avoid moving the elbow away from the side of the body and to always keep the palm of the hand outstretched (Fig. 4). During elbow pronation-supination, the starting position was seated in a chair, bringing the side of the body closer to a stretcher or a flat surface. The forearm rested on the stretcher and the arm was attached to the body. Arm and forearm formed $90^{\circ}$. The hand had to protrude from the 
278 supporting surface. The hand was placed sideways, with the thumb pointing towards the ceiling 279 and the rest of the fingers of the hand extended together. During pronation the subject rotated $280 \mathrm{his} /$ her hand, trying to make the palm face the ground (Fig. 5). Flexion-extension wrist 281 movements were evaluated while seated in a chair, bringing the side of the body closer to the 282 stretcher or a flat surface. The forearm rested on the stretcher. The hand had to protrude from the 283 supporting surface. In the neutral position, the hand was placed with the back facing the ceiling, 284 fingers extended and together. During wrist flexion, the subject moved the hand, trying to keep 285 the tips of the fingers pointed towards the floor and keeping the hand stiff. During wrist

286

287

288

289

290

291

292

293

294

295

296

297

298

299

300

301

302

303

304

305

306

307

308

309

310

311

312

313

314

315

316

317

318 extension, the subject moved the hand, trying to keep the tips of the fingers pointed towards the ceiling. In radial-ulnar deviation, the starting position was the same, but the forearm and palm of the hand were supported on the stretcher. During the radial deviation, the subject made a lateral tilt, towards the direction in which his thumb was, moving his/her fingers away from the middle line that crosses the hand longitudinally. During the ulnar deviation, the subject made a lateral tilt, towards the direction in which his/her little finger was, moving the fingers away from the midline (Fig. 6).

There was not any warm-up exercise, but the subject was encouraged to repeat the movement with the examiner to make sure the task was understood and there was no cause of pain. All the movements were active and, consequently, the examiner did not help the participant to attain his/her ROM end-feel. For both joints, each at its own time, the technician indicated which rater should perform the evaluation in the first position (according to the random order previously generated), while the other waited outside the room. The selected rater placed the goniometer, as well as the inertial sensors, in the subject's joint. Once all these steps had been taken, the subject was positioned in the initial or neutral position and the technician was asked to calibrate the sensors in such a way that the device considered this point as zero degrees. At this stage, the subject started the movement actively. The rater, who was also ready with the goniometer in a zero position, followed the movement of the subject's limb with the moving arm of the goniometer and encouraged the subject to make the maximum effort in order to achieve the end of the active range. When this point was reached, the examiner read the measurement of the goniometer and communicated it to the technician, who simultaneously read, in the software tool, the measure registered by the sensors. Both measurements were collected in the template and the subject was instructed to return to the zero position. This procedure was repeated three times calibrating between repetitions. After these repetitions, the procedure followed with the next movement planned to complete the set of movements. All the data collected is available as supplementary materials of this article (Data S1 and S2).

\section{Statistical analysis}

The statistical analysis was performed using IBM ${ }^{\circledR}$ SPSS Statistics statistical package, version 25. A Shapiro-Wilk test was carried out to test the normality of the data distributions. This test is recommended for a sample size of less than 50 (Ahmad \& Khan Sherwani, 2015). The statistical 
319 significance level was set at $\mathrm{p}<0.05$. Mean and standard deviation (SD) were computed 320 subsequently to characterize the ROM measured with the goniometer and the inertial sensors for 321 elbow and wrist. For that purpose, the average value of three repetitions of each distinctive 322 movement was used.

323

324 To evaluate validity and reliability, the correlation coefficients $\mathrm{r}^{2}$ and ICC were calculated 325 (Portney \& Watkins, 2015). ICC model $(3, \mathrm{k})$ for the intra-rater analysis and the ICC model $(2$, 326 k) for the inter-rater analysis were used. The SEM and the MDC at the $90 \%$ confidence level 327 were calculated for both measuring instruments (McKenna, Cunningham \& Straker, 2004). SEM 329 can be estimated from the ICC:

331

332

333

$S E M=S D \sqrt{1-I C C}$,

334

335

336

where SD is the standard deviation of the measures. MDC is useful to characterize the effectiveness of a device to detect changes in the measured variable ant it can be calculated from the SEM (Portney \& Watkins, 2015):

337

338

339

340

341

342

$M D C_{90}=1,65 \times S E M \times \sqrt{2}$.

Finally, a Bland Altman analysis was conducted. This graphical method analyzes the agreement between two different measurement methods. It uses the mean and the standard deviation to create a scatterplot with limits of agreement, in which the difference between the two paired measurements is plotted against the mean of the two measurements. While the mean difference is the estimated bias, the standard deviation measures the random fluctuations around this mean

343 (Doğan, 2018).

344

345

346

347

348

349

350

351

352

353

354

\section{Results}

The Shapiro-Wilk test indicated that the distributions with which we are working were in all cases normal ( $p$-value $<0.05$ ). Table 2 shows the mean and the SD for the measures obtained with the goniometer and the sensor for all the movements of both joints. Pronation and supination ROM for the elbow had the greatest variation.

Tables 3 and 4 present $\mathrm{r}^{2}$ and ICC, with its $95 \%$ confidence interval (CI), between the measures taken simultaneously by the goniometer and the inertial sensors. Regarding the elbow results, $\mathrm{r}^{2}$ values ranged between 0.47 and 0.95 involving all the movements in the two sessions. The lowest values for $\mathrm{r}^{2}$ were found in pronation (0.47) during the first session for examiner $\mathrm{B}$, although examiner A obtained higher values. ICC values varied from 0.78 to 0.99 . In the case of the wrist, $\mathrm{r}^{2}$ and ICC values varied between $0.82-0.96$ and $0.95-0.99$, respectively. 
358 The intra-rater and inter-rater reliability results of the elbow are shown in Tables 5 and 6 . The

359

360

361

362

363

364

365

366

367

368

369

370

371

372

373

374

375

376

377

378

379

380

381

382

383

384

385

386

387

388

389

390

391

392

393

394

395

396

397

intra-rater analysis of the elbow assessed by the goniometer yielded ICC values ranging from 0.62 to 0.91 , while the sensors' values ranged from 0.79 to 0.96 . In both cases the lowest values belong to pronation movements. With regard to inter-rater reliability of elbow ROM, ICC values for the sensors ranged between 0.94 and 0.97 , while for the goniometer ranged between 0.83 and 0.95 .

Regarding the intra-rater analysis of the wrist (Table 7), ICC values were between 0.81 and 0.93 both for the goniometer and the inertial sensors. The inter-rater analysis of the wrist yielded slightly greater ICC values for the inertial sensors (0.93-0.99) compared with those from the goniometer (0.92-0.97) (Table 8).

The SEM and $\mathrm{MDC}_{90}$ for both elbow and wrist for the sensors are for most types of movements less than or equal to those of the goniometer (Tables 5,6,7,8), as it was expected since these values are vary inversely with the magnitude of the ICC, and the ICC of the sensors for most of the cases is equal to or greater than that of the goniometer.

Figures 7 and 8 show the Bland-Altman plots for the different movements of the elbow and wrist. These plots reflect a good agreement between the measurements of the inertial sensors and the goniometer.

\section{Discussion}

According to Table 2, similar active ROM values were obtained for the goniometer and sensors both for elbow and wrist. When using a t-test to compare the distributions of the measurements of each instrument for pronation and supination, which had the greatest variability between raters, the p-values were 0.28 for pronation and 0.56 for supination; i.e., there are no statistically significant differences between the measurements of both instruments. For the rest of the movements, the mean value of the measures obtained with the sensor and the goniometer had a maximum difference of $1^{\circ}$, even for the measures taken by the two different physiotherapists, which is an excellent agreement.

The results of Table 2 were compared with the normal ROM values of the literature. Flexion elbow ROM, for both the goniometer and the inertial sensors, ranged between $150^{\circ} \pm 7^{\circ}$ and $150^{\circ} \pm 9^{\circ}$; very similar to the $150^{\circ}$ value reported by the American Academy of Orthopaedic Surgeons (AAOS) (Norkin \& White, 2009). Pronation and supination were lower on average than those of the AAOS and the American Medical Association (AMA), which reported $80^{\circ}$ of pronation and supination ROM. Since this affected both goniometric and sensors measurements, it was thought it could have been due to a low flexion capacity of some subjects performing such movements or due to lack of motivation during the experiment. In the case of the active ROM of the wrist, all the movements presented values consistent with the ranges of normality described 
398

399

400

401

402

403

404

405

406

407

408

409

410

411

412

413

414

415

416

417

418

419

420

421

422

423

424

425

426

427

428

429

430

431

432

433

434

435

436

437

in the literature, both measured by goniometer and sensors. These values were slightly higher when compared to the AAOS and AMA values, but close to those from Green and Wolf's ROM studies (Greene \& Wolf, 1989). For instance, in the case of radial deviation, the present experiment yielded values ranging from $26^{\circ} \pm 7^{\circ}$ to $27^{\circ} \pm 7^{\circ}$, comparable with $25.4^{\circ} \pm 2^{\circ}$ from the later, while AAOS and AMA reported $20^{\circ}$.

Table 3 shows a high concordance between the measurements taken by the goniometer and the sensors (ICC $>0.78$ always, for most of the cases ICC $>0.90$ ). The lowest ICC were obtained for pronation movements. Pronation involves great arthrokinematics complexity since the radius is placed above the ulna during this movement, unlike the supination where the bones are parallel. This hinders its measurement with any instrument since the instruments cannot rotate in unison with the bone to accurately measure the degrees of rotation. We also believe that the movement of the forearm's skin could be affecting the measurements of the inertial sensors. This hypothesis seems to be supported by (Muller et al., 2017), who found higher RMS errors for pronation and supination related to flexo-extension when using manual alignment of the sensors. Placing the sensor on subject' hand instead of forearm might have improved the results of prono-supination measurement.

ICC was particularly good for the wrist (ICC $\geq 0.95$ ), considering all the movements in both sessions (Table 4). With regard to reliability, the assessment of the elbow with sensors yielded an ICC $\geq 0.83$ and ICC $\geq 0.94$ for intra-rater and inter-rater analysis respectively, higher than those resulting from the goniometer measurements (Table 5 and Table 6). The SEM and $\mathrm{MDC}_{90}$ values for both elbow and wrist were lower in the case of the sensors than in the case of the goniometer, particularly in the inter-rater analysis of both joints (Table 6 and Table 8). This suggests that the sensors can identify subtler ROM variations when compared to the goniometer.

In the literature we can find papers that use inertial sensors to estimate the movement of the upper limb (Tian et al., 2015; Zhou et al., 2008; Zhang, Wong \& Wu, 2011; Robert-Lachaine et al., 2017; Ertzgaard et al., 2016), but many of them do not conduct a study of the validity and reliability of their ROM measurements compared with the measurements obtained with a goniometer. The only paper we have found with which we can directly compare our results is (Behnoush et al., 2016). In this study inertial sensors of an iPhone ${ }^{\mathrm{TM}}$ were compared with a goniometer for elbow's ROM measurement. The iPhone ${ }^{\mathrm{TM}}$ reliability values reported were greater than ours (ICC between 0.95-0.98); however those of the goniometer were lower than ours (ICC between 0.77-0.91), which also led to smaller ICC values in the assessment of concurrent validity: ICC of $0.84,0.90$ and 0.96 for flexion, pronation and supination, compared with our ICC values of $0.90,0.88$ and 0.97 (average value for both raters). The goniometer reliability values of Behnoush et al. are lower than ours likely because their measurements were carried out by doctors who received training on how to measure the ROM with the goniometer to conduct the study, while in our case physiotherapists with years of experience in the usage of the

Peer] reviewing PDF | (2020:02:46039:1:1:NEW 18 Jun 2020) 
438 goniometer took the measurements. Behnoush's study only analyzed intra-rater validity of the 439 elbow, not inter-rater validity, thus no comparison with our inter-rater results is possible. We 440 have not found any study assessing the validity and reliability of wrist ROM measurements taken 441 with inertial sensors with which we could compare our results.

442

443 Regarding the limitations of the present study, the intra-rater outcomes could have been limited

444

445

446

447

448

449

450

451

452

453

454

455

456

457

458

459

460

461

462

463

464

465

466

467

468

469

470

471

472

473

474

475

476

477 by the absence of a warm-up phase. This type of practice is commonly implemented and can improve reliability since there are specific conditions that can influence the joint ROM from one session to the next. Moreover, during the testing phase it was observed that, in some cases where the participants had great joint flexibility, the sensor was not able to capture accurately the rotation of the forearm because the skin was stretched and twisted and the sensor strap could not be held in the proper position. This can be corrected with the use of anti-slip silicone printed in the inner side of the strap, which would have resulted in greater adherence to the arm. A reduction in the size of the inertial sensors could also be an improvement. This would permit a more stable placing of the sensors, resulting in more accurate measurements.

The symmetrical movements of the joint (radial-ulnar deviation, flexion-extension, etc.) were performed partially rather than completely. That was the case for both elbow and wrist. For instance, in the case of wrist deviations, three repetitions of the radial deviation and then three repetitions of the ulnar deviation were performed, always returning to the neutral starting point. An alternative would have been to perform the full or complete range, i.e., three repetitions of maximum deviation from radial to ulnar. There is evidence that this second procedure could yield more precise ROM because in the first case the subject's limb does not exactly return to its starting point for each new repetition of the motion (Raya et al., 2018).

\section{Conclusions}

The measurements of the elbow and wrist ROM taken with inertial sensors have a high agreement with those taken with a goniometer. For the elbow the ICC values range from 0.78 to 0.99, while for the wrist they range from 0.95 to 0.99 (Tables 3 and 4). Furthermore, the ROM values obtained with the sensors are in agreement with the normal ROM values published in the literature (Table 2). These findings support the validity of their measures.

The reliability of their measurements in intra-rater scenarios compared to that of a goniometer is similar or slightly superior, with ICC values ranging from 0.62 to 0.96 for the elbow, and from 0.83 to 0.95 for the wrist in the case of the goniometer, compared with ICC values ranging from 0.83 to 0.96 for the elbow, and from 0.94 to 0.97 for the wrist in the case of the sensors (Tables 5 and 6). In inter-rater scenarios, the reliability of the sensors is higher compared to that of the goniometer for the elbow; while the ICC values of the goniometer range from 0.92 to 0.97 , for the sensors they range from 0.93 to 0.99 (Table 8). In the case of the wrist the inter-rater reliability is similar in both cases, ranging from 0.81 to 0.93 (Table 7). 
478 Overall, our results support the usage of inertial sensors to evaluate the ROM of elbow and wrist. 479 Furthermore, inertial sensors present advantages over goniometry with regard to the easiness of 480 usage, which in case of the goniometer is more dependent on the experience of the practitioner 481 locating anatomical references or performing the reading of measurements (Chapleau et al., 482 2011). They also avoid the need for holding the arms of the goniometer while taking a 483 measurement, or for stabilization during the end-feel range of motion readout. And, given that

484

485

486

487

488

489

490

491

492

493

494

495

496

497

498

499

500

501

502

503

504

505

506

507

508

509

510

511

512

513

514

515

516

517

518

519 the measurements they provide are already digital, they can be recoded automatically using a PC, and even incorporated into the patient's electronic medical record. All these advantages make inertial sensors an interesting solution to replace the traditional goniometer.

The easy connectivity of inertial sensors with computing devices enables their usage in virtual rehabilitation scenarios through videogames and/or virtual environments. Given than rehabilitation success is greatly dependent on patient's motivation, innovative upper-limb rehabilitation procedures combining inertial sensors with serious games are being currently addressed (Giggins, Sweeney \& Caulfield, 2014; Callejas-Cuervo, Gutierrez \& Hernandez, 2017). As future work we plan to explore the usage of inertial sensors and serious video games for the rehabilitation of the upper limb. We also would like to repeat this study with patients, instead of asymptomatic volunteers. This would provide a deeper understanding of specific musculoskeletal data and exercise rehabilitation programs for the elbow and wrist joints.

\section{Acknowledgements}

The authors of this work would like to thank the volunteers of the experimental trials for coming and contributing selflessly to this project.

\section{References}

Ahmad N, Ghazilla RAR, Khairi NM, Kasi V. 2013. Reviews on Various Inertial Measurement Unit (IMU) Sensor Applications. International Journal of Signal Processing Systems:256262. DOI: 10.12720/ijsps.1.2.256-262.

Ahmad F, Khan Sherwani RA. 2015. Power comparison of various normality tests. Pakistan Journal of Statistics and Operation Research 11:331-345. DOI: 10.18187/pjsor.v11i3.845.

Bai L, Pepper MG, Yan Y, Spurgeon SK, Sakel M, Phillips M. 2015. Quantitative Assessment of Upper Limb Motion in Neurorehabilitation Utilizing Inertial Sensors. IEEE Transactions on Neural Systems and Rehabilitation Engineering 23:232-243. DOI: 10.1109/TNSRE.2014.2369740.

Behnoush B, Tavakoli N, Bazmi E, Nateghi Fard F, Pourgharib Shahi MH, Okazi A, Mokhtari T. 2016. Smartphone and Universal Goniometer for Measurement of Elbow Joint Motions: A Comparative Study. Asian journal of sports medicine 7:e30668. DOI: 10.5812/asjsm.30668. Bertomeu-Motos A, Lledó LD, Díez JA, Catalan JM, Ezquerro S, Badesa FJ, Garcia-Aracil N. 2015. Estimation of human arm joints using two wireless sensors in robotic rehabilitation tasks. Sensors (Switzerland) 15:30571-30583. DOI: 10.3390/s151229818.

Boddy KJ, Marsh JA, Caravan A, Lindley KE, Scheffey JO, O’Connell ME. 2019. Exploring 
520

521

522

523

524

525

526

527

528

529

530

531

532

533

534

535

536

537

538

539

540

541

542

543

544

545

546

547

548

549

550

551

552

553

554

555

556

557

558

559

560

561

562

563

564

565

wearable sensors as an alternative to marker-based motion capture in the pitching delivery. PeerJ 2019. DOI: 10.7717/peerj.6365.

Callejas-Cuervo M, Gutierrez RM, Hernandez AI. 2017. Joint amplitude MEMS based measurement platform for low cost and high accessibility telerehabilitation: Elbow case study. Journal of Bodywork and Movement Therapies 21:574-581. DOI: 10.1016/j.jbmt.2016.08.016.

Carmona-Pérez C, Garrido-Castro JL, Vidal FT, Alcaraz-Clariana S, García-Luque L, Alburquerque-Sendín F, Rodrigues-De-Souza DP. 2020. Concurrent validity and reliability of an inertial measurement unit for the assessment of craniocervical range of motion in subjects with cerebral palsy. Diagnostics 10. DOI: 10.3390/diagnostics10020080.

Chapleau J, Canet F, Petit Y, Laflamme GY, Rouleau DM. 2011. Validity of goniometric elbow measurements: Comparative study with a radiographic method. Clinical Orthopaedics and Related Research 469:3134-3140. DOI: 10.1007/s11999-011-1986-8.

Chen KH, Chen PC, Liu KC, Chan CT. 2015. Wearable sensor-based rehabilitation exercise assessment for knee osteoarthritis. Sensors (Switzerland) 15:4193-4211. DOI: $10.3390 / \mathrm{s} 150204193$.

Doğan NÖ. 2018. Bland-Altman analysis: A paradigm to understand correlation and agreement. Turkish Journal of Emergency Medicine 18:139-141. DOI: 10.1016/J.TJEM.2018.09.001.

Ertzgaard P, Öhberg F, Gerdle B, Grip H. 2016. A new way of assessing arm function in activity using kinematic Exposure Variation Analysis and portable inertial sensors - A validity study. Manual Therapy 21:241-249. DOI: 10.1016/j.math.2015.09.004.

Filippeschi A, Schmitz N, Miezal M, Bleser G, Ruffaldi E, Stricker D. 2017. Survey of motion tracking methods based on inertial sensors: A focus on upper limb human motion. Sensors (Switzerland) 17. DOI: 10.3390/s17061257.

Gajdosik R, Bohannon R. 1987. Clinical measurement of range of motion. Review of goniometry emphasizing reliability and validity. Physical Therapy 67:1867-1872. DOI: $10.1093 / \mathrm{ptj} / 67.12 .1867$.

GBD 2017 Disease and Injury Incidence and Prevalence Collaborators SL, 2018. Global, regional, and national incidence, prevalence, and years lived with disability for 354 diseases and injuries for 195 countries and territories, 1990-2017: a systematic analysis for the Global Burden of Disease Study 2017. Lancet (London, England) 392:1789-1858. DOI: 10.1016/S0140-6736(18)32279-7.

Giggins OM, Sweeney KT, Caulfield B. 2014. Rehabilitation exercise assessment using inertial sensors: a cross-sectional analytical study. Journal of NeuroEngineering and Rehabilitation 11:158. DOI: 10.1186/1743-0003-11-158.

Greene BR, Rutledge S, McGurgan I, McGuigan C, O’Connell K, Caulfield B, Tubridy N. 2015. Assessment and Classification of Early-Stage Multiple Sclerosis with Inertial Sensors: Comparison Against Clinical Measures of Disease State. IEEE Journal of Biomedical and Health Informatics 19:1356-1361. DOI: 10.1109/JBHI.2015.2435057.

Greene BL, Wolf SL. 1989. Upper extremity joint movement: Comparison of two measurement devices. Archives of Physical Medicine and Rehabilitation 70:288-290. DOI: 10.5555/uri:pii:0003999389901470.

Iwasaki Y, Hirotomi T. 2015. Using Motion Sensors to Support Seating and Positioning Assessments of Individuals with Neurological Disorders. In: Procedia Computer Science. Elsevier B.V., 113-122. DOI: 10.1016/j.procs.2015.09.255.

Kolber MJ, Fuller C, Marshall J, Wright A, Hanney WJ. 2012. The reliability and concurrent

Peer] reviewing PDF | (2020:02:46039:1:1:NEW 18 Jun 2020) 
566

567

568

569

570

571

572

573

574

575

576

577

578

579

580

581

582

583

584

585

586

587

588

589

590

591

592

593

594

595

596

597

598

599

600

601

602

603

604

605

606

607

608

609

610

611

validity of scapular plane shoulder elevation measurements using a digital inclinometer and goniometer. Physiotherapy theory and practice 28:161-8. DOI:

10.3109/09593985.2011.574203.

McKenna L, Cunningham J, Straker L. 2004. Inter-tester reliability of scapular position in junior elite swimmers. Physical Therapy in Sport 5:146-155. DOI: 10.1016/j.ptsp.2004.05.001.

Mehta SP, Barker K, Bowman B, Galloway H, Oliashirazi N, Oliashirazi A. 2017. Reliability, Concurrent Validity, and Minimal Detectable Change for iPhone Goniometer App in Assessing Knee Range of Motion. Journal of Knee Surgery 30:577-584. DOI: 10.1055/s0036-1593877.

Muller P, Begin MA, Schauer T, Seel T. 2017. Alignment-Free, Self-Calibrating Elbow Angles Measurement Using Inertial Sensors. IEEE Journal of Biomedical and Health Informatics 21:312-319. DOI: 10.1109/JBHI.2016.2639537.

Norkin CC, White DJ. 2009. Measurement of joint motion : a guide to goniometry. F.A. Davis. Portney L, Watkins M. 2015. Foundations of Clinical Research: Applications to Practice (3rd Edition). :912. DOI: 10.1331/JAPhA.2011.10034.

Raya R, Garcia-Carmona R, Sanchez C, Urendes E, Ramirez O, Martin A, Otero A, Raya R, Garcia-Carmona R, Sanchez C, Urendes E, Ramirez O, Martin A, Otero A. 2018. An Inexpensive and Easy to Use Cervical Range of Motion Measurement Solution Using Inertial Sensors. Sensors 18:2582. DOI: 10.3390/s18082582.

Raya R, Rocon E, Gallego JA, Ceres R, Pons JL. 2012. A Robust Kalman Algorithm to Facilitate Human-Computer Interaction for People with Cerebral Palsy, Using a New Interface Based on Inertial Sensors. Sensors (Peterboroug 12:3049-3067. DOI: 10.3390/s120303049.

Raya R, Rocon E, Urendes E, Velasco MA, Clemotte A, Ceres R. 2015. Assistive robots for physical and cognitive rehabilitation in cerebral palsy. Springer Tracts in Advanced Robotics 106:133-156. DOI: 10.1007/978-3-319-12922-8_5.

Roach S, San Juan JG, Suprak DN, Lyda M. 2013. Concurrent validity of digital inclinometer and universal goniometer in assessing passive hip mobility in healthy subjects. International journal of sports physical therapy 8:680-8.

Robert-Lachaine X, Mecheri H, Larue C, Plamondon A. 2017. Validation of inertial measurement units with an optoelectronic system for whole-body motion analysis. Medical and Biological Engineering and Computing 55:609-619. DOI: 10.1007/s11517-016-15372.

Roldán-Jiménez C, Cuesta-Vargas AI. 2016. Age-related changes analyzing shoulder kinematics by means of inertial sensors. Clinical Biomechanics 37:70-76. DOI:

10.1016/j.clinbiomech.2016.06.004.

Sacco G, Turpin JM, Marteu A, Sakarovitch C, Teboul B, Boscher L, Brocker P, Robert P, Guerin O. 2015. Inertial sensors as measurement tools of elbow range of motion in gerontology. Clinical Interventions in Aging 10:491-497. DOI: 10.2147/CIA.S70452.

Tian Y, Meng X, Tao D, Liu D, Feng C. 2015. Upper limb motion tracking with the integration of IMU and Kinect. Neurocomputing 159:207-218. DOI: 10.1016/j.neucom.2015.01.071.

Tsushima H, Morris ME, McGinley J. 2003. Test-Retest Reliability and Inter-Tester Reliability of Kinematic Data from a Three-Dimensional Gait Analysis System. Journal of the Japanese Physical Therapy Association 6:9-17. DOI: 10.1298/jjpta.6.9.

Vauclair F, Aljurayyan A, Abduljabbar FH, Barimani B, Goetti P, Houghton F, Harvey EJ, Rouleau DM. 2018. The smartphone inclinometer: A new tool to determine elbow range of motion? European Journal of Orthopaedic Surgery and Traumatology 28:415-421. DOI:

Peer] reviewing PDF | (2020:02:46039:1:1:NEW 18 Jun 2020) 
$612 \quad 10.1007 / \mathrm{s} 00590-017-2058-\mathrm{x}$.

613 Wells D, Alderson J, Camomilla V, Donnelly C, Elliott B, Cereatti A. 2019. Elbow joint

614 kinematics during cricket bowling using magneto-inertial sensors: A feasibility study.

615 Journal of Sports Sciences 37:515-524. DOI: 10.1080/02640414.2018.1512845.

616 Wells D, Cereatti A, Camomilla V, Donnelly CJ, Elliott B, Alderson J. 2015. A Calibration

617 Procedure for MIMU Sensors Allowing for the Calculation of Elbow Angles. :1-4.

618 Wiesener C, Seel T, Axelgaard J, Horton R, Niedeggen A, Schauer T. 2019. An Inertial Sensor-

619 based Trigger Algorithm for Functional Electrical Stimulation-Assisted Swimming in

620 Paraplegics. IFAC-PapersOnLine 51:278-283. DOI: 10.1016/j.ifacol.2019.01.039.

621 Yahya M, Shah JA, Kadir KA, Yusof ZM, Khan S, Warsi A. 2019. Motion capture sensing

622 techniques used in human upper limb motion: a review. Sensor Review 39:504-511. DOI:

$623 \quad 10.1108 /$ SR-10-2018-0270.

624 Zhang ZQ, Wong WC, Wu JK. 2011. Ubiquitous human upper-limb motion estimation using

625 wearable sensors. IEEE Transactions on Information Technology in Biomedicine 15:513-

626 521. DOI: 10.1109/TITB.2011.2159122.

627 Zhou H, Stone T, Hu H, Harris N. 2008. Use of multiple wearable inertial sensors in upper limb 628 motion tracking. Medical Engineering and Physics 30:123-133. DOI:

$629 \quad$ 10.1016/j.medengphy.2006.11.010.

630 


\section{Table 1 (on next page)}

Subject's demographic characteristics

BMI: Body Mass Index

Values presented as mean \pm standard deviation (SD) 


\section{Table 1:}

2 Subject's demographic characteristics

\begin{tabular}{|c|c|c|c|c|c|}
\hline Subjects & $\mathrm{n}$ & Age (years) & Height $(\mathrm{m})$ & Weight $(\mathrm{kg})$ & BMI $\left(\mathrm{kg} / \mathrm{m}^{2}\right)$ \\
\hline Male & $20(69 \%)$ & $24.10 \pm 3.86$ & $1.79 \pm 0.08$ & $76.19 \pm 12.71$ & $23.67 \pm 3.19$ \\
\hline Female & $9(31 \%)$ & $21.33 \pm 1.50$ & $1.62 \pm 0.09$ & $58.78 \pm 9.65$ & $22.16 \pm 1.77$ \\
\hline
\end{tabular}

3 BMI: Body Mass Index

4 Values presented as mean \pm standard deviation (SD) 


\section{Table 2 (on next page)}

Descriptive statistics of elbow and wrist ROM measured by goniometer and inertial sensor, organized by rater.

ROM: Range of motion

SD: Standard deviation 


\section{Table 2:}

2 Descriptive statistics of elbow and wrist ROM measured by goniometer and inertial sensor, 3 organized by rater.

\begin{tabular}{|l|l|c|c|c|c|c|c|c|}
\hline & & \multicolumn{3}{|c|}{ Elbow mean ROM $\left({ }^{\circ}\right) \pm \mathrm{SD}\left({ }^{\circ}\right)$} & \multicolumn{3}{|c|}{ Wrist mean ROM $\left(^{\circ}\right) \pm$ SD $\left({ }^{\circ}\right)$} \\
\hline & & Flexion & Pronation & Supination & Flexion & Extension & $\begin{array}{c}\text { Radial } \\
\text { deviation }\end{array}$ & $\begin{array}{c}\text { Ulnar } \\
\text { deviation }\end{array}$ \\
\hline \multirow{2}{*}{$\mathrm{A}$} & Goniometer & $150^{\circ} \pm 7^{\circ}$ & $64^{\circ} \pm 11^{\circ}$ & $67^{\circ} \pm 14^{\circ}$ & $82^{\circ} \pm 10^{\circ}$ & $68^{\circ} \pm 9^{\circ}$ & $27^{\circ} \pm 7^{\circ}$ & $43^{\circ} \pm 8^{\circ}$ \\
\cline { 2 - 9 } & Sensor & $150^{\circ} \pm 8^{\circ}$ & $61^{\circ} \pm 10^{\circ}$ & $66^{\circ} \pm 13^{\circ}$ & $83^{\circ} \pm 11^{\circ}$ & $67^{\circ} \pm 9^{\circ}$ & $27^{\circ} \pm 7^{\circ}$ & $43^{\circ} \pm 8^{\circ}$ \\
\hline \multirow{2}{*}{$\mathrm{B}$} & Goniometer & $150^{\circ} \pm 9^{\circ}$ & $63^{\circ} \pm 11^{\circ}$ & $69^{\circ} \pm 13^{\circ}$ & $82^{\circ} \pm 11^{\circ}$ & $66^{\circ} \pm 9^{\circ}$ & $26^{\circ} \pm 7^{\circ}$ & $43^{\circ} \pm 8^{\circ}$ \\
\cline { 2 - 8 } & Sensor & $150^{\circ} \pm 9^{\circ}$ & $61^{\circ} \pm 10^{\circ}$ & $67^{\circ} \pm 13^{\circ}$ & $83^{\circ} \pm 11^{\circ}$ & $66^{\circ} \pm 9^{\circ}$ & $27^{\circ} \pm 6^{\circ}$ & $43^{\circ} \pm 9^{\circ}$ \\
\hline
\end{tabular}

4 ROM: Range of motion.

5 SD: Standard deviation. 


\section{Table 3 (on next page)}

$r^{2}$ and ICC (with 95\% Cl) for the elbow ROM measurements taken by the goniometer and the sensors organized by rater and session. 


\section{Table 3.}

$2 \mathbf{r}^{2}$ and ICC (with 95\% CI) for the elbow ROM measurements taken by the goniometer and 3 the sensors organized by rater and session.

\begin{tabular}{lccc|ccc}
\hline & \multicolumn{3}{c}{ 1st session } & \multicolumn{3}{c}{ 2nd session } \\
\hline Rater A & ICC & CI 95\% & $\mathbf{r}^{\mathbf{2}}$ & ICC & CI 95\% \\
Flexion & 0.68 & 0.90 & {$[0.78-0.95]$} & 0.72 & 0.90 & {$[0.79-0.95]$} \\
Pronation & 0.59 & 0.84 & {$[0.62-0.93]$} & 0.76 & 0.91 & {$[0.76-0.96]$} \\
Supination & 0.81 & 0.94 & {$[0.86-0.97]$} & 0.95 & 0.99 & {$[0.97-0.99]$} \\
\hline Rater B & & & & & & \\
Flexion & 0.64 & 0.89 & {$[0.77-0.95]$} & 0.83 & 0.95 & {$[0.90-0.98]$} \\
Pronation & 0.47 & 0.78 & {$[0.51-0.90]$} & 0.70 & 0.91 & {$[0.81-0.96]$} \\
Supination & 0.90 & 0.97 & {$[0.93-0.99]$} & 0.81 & 0.94 & {$[0.87-0.97]$} \\
\hline
\end{tabular}

4 


\section{Table 4 (on next page)}

$\mathrm{r}^{2}$ and ICC (with $95 \% \mathrm{CI}$ ) for the wrist ROM measurements taken by the goniometer and the sensors organized by rater and session. 
1 Table 4.

$2 \mathbf{r}^{2}$ and ICC (with 95\% CI) for the wrist ROM measurements taken by the goniometer and

3 the sensors organized by rater and session.

\begin{tabular}{lccc|ccc}
\hline & \multicolumn{3}{c}{$\mathbf{1}^{\text {st }}$ session } & \multicolumn{3}{c}{$\mathbf{2}^{\text {nd }}$ session } \\
\hline Rater A & $\mathbf{r}^{\mathbf{2}}$ & ICC & $\mathbf{C I ~ 9 5 \%}$ & $\mathbf{r}^{\mathbf{2}}$ & $\mathbf{I C C}$ & $\mathbf{C I} 95 \%$ \\
$\begin{array}{l}\text { Flexion } \\
\text { Extension }\end{array}$ & 0.94 & 0.98 & {$[0.96-0.99]$} & 0.94 & 0.99 & {$[0.97-0.99]$} \\
$\begin{array}{l}\text { Radial } \\
\text { deviation }\end{array}$ & 0.95 & 0.99 & {$[0.97-0.99]$} & 0.91 & 0.98 & {$[0.95-0.99]$} \\
$\begin{array}{l}\text { Ulnar } \\
\text { deviation }\end{array}$ & 0.87 & 0.97 & {$[0.93-0.99]$} & 0.89 & 0.97 & {$[0.93-0.93]$} \\
\hline $\begin{array}{l}\text { Rater B } \\
\text { Flexion }\end{array}$ & 0.88 & 0.97 & {$[0.93-0.98]$} & 0.96 & 0.99 & {$[0.97-0.99]$} \\
$\begin{array}{l}\text { Extension } \\
\begin{array}{l}\text { Radial } \\
\text { deviation }\end{array}\end{array}$ & 0.89 & 0.97 & {$[0.93-0.98]$} & 0.85 & 0.96 & {$[0.91-0.98]$} \\
$\begin{array}{l}\text { Ulnar } \\
\text { deviation }\end{array}$ & 0.82 & 0.95 & {$[0.89-0.98]$} & 0.92 & 0.98 & {$[0.95-0.99]$} \\
\hline
\end{tabular}

4 


\section{Table 5 (on next page)}

Intra-rater reliability analysis of goniometer and inertial sensor assessing elbow ROM. 


\section{Table 5.}

2 Intra-rater reliability analysis of goniometer and inertial sensor assessing elbow ROM.

\begin{tabular}{lcccc|cccc}
\hline \multicolumn{5}{c}{ Goniometer } & \multicolumn{5}{c}{ Sensor } \\
\hline Rater A & ICC & CI 95\% & SEM & MDC $_{\mathbf{9 0}}$ & ICC & CI 95\% & SEM & MDC $_{\mathbf{9 0}}$ \\
Flexion & 0.86 & {$[0.71-0.94]$} & $4^{\circ}$ & $8^{\circ}$ & 0.79 & {$[0.56-0.90]$} & $5^{\circ}$ & $13^{\text {o }}$ \\
Pronation & 0.74 & {$[0.44-0.88]$} & $8^{\circ}$ & $19^{\circ}$ & 0.86 & {$[0.71-0.93]$} & $5^{\circ}$ & $13^{\text {o }}$ \\
Supination & 0.96 & {$[0.90-0.98]$} & $4^{\circ}$ & $10^{\circ}$ & 0.92 & {$[0.84-0.97]$} & $5^{\circ}$ & $12^{\text {o }}$ \\
\hline Rater B & & & & & & & & \\
Flexion & 0.75 & {$[0.46-0.88]$} & $6^{\circ}$ & $14^{\circ}$ & 0.83 & {$[0.63-0.92]$} & $5^{\circ}$ & $12^{\circ}$ \\
Pronation & 0.62 & {$[0.21-0.82]$} & $10^{\circ}$ & $23^{\circ}$ & 0.89 & {$[0.77-0.95]$} & $5^{\circ}$ & $11^{\circ}$ \\
Supination & 0.91 & {$[0.80-0.95]$} & $6^{\circ}$ & $14^{\circ}$ & 0.96 & {$[0.90-0.98]$} & $4^{\circ}$ & $9^{\circ}$ \\
\hline
\end{tabular}

3

4 
Table 6(on next page)

Inter-rater reliability analysis of goniometer and inertial sensor assessing elbow ROM. 
1 Table 6.

2 Inter-rater reliability analysis of goniometer and inertial sensor assessing elbow ROM.

\begin{tabular}{|c|c|c|c|c|c|c|c|c|}
\hline & \multicolumn{4}{|c|}{ Goniometer } & \multicolumn{4}{|c|}{ Sensor } \\
\hline & ICC & CI 95\% & SEM & $\mathrm{MDC}_{90}$ & ICC & CI 95\% & SEM & $\mathrm{MDC}_{90}$ \\
\hline \multicolumn{9}{|l|}{ 1st session } \\
\hline Flexion & 0.86 & {$[0.71-0.93]$} & $4^{\circ}$ & $9^{\circ}$ & 0.95 & [0.89-0.97] & $2^{\circ}$ & $6^{\circ}$ \\
\hline Pronation & 0.93 & [0.85-0.97] & $5^{\circ}$ & $11^{\circ}$ & 0.95 & [0.89-0.94] & $3^{\circ}$ & $8^{\circ}$ \\
\hline Supination & 0.95 & [0.90-0.98] & $4^{\circ}$ & $10^{\circ}$ & 0.96 & [0.91-0.98] & $4^{\circ}$ & $9^{\circ}$ \\
\hline \multicolumn{9}{|l|}{ 2nd session } \\
\hline Flexion & 0.92 & {$[0.82-0.96]$} & $3^{\circ}$ & $8^{\circ}$ & 0.97 & [0.93-0.98] & $3^{\circ}$ & $6^{\circ}$ \\
\hline Pronation & 0.83 & [0.54-0.93] & $6^{\circ}$ & $14^{\circ}$ & 0.94 & [0.88-0.97] & $4^{\circ}$ & $8^{\circ}$ \\
\hline Supination & 0.91 & [0.74-0.96] & $6^{\circ}$ & $14^{\circ}$ & 0.97 & [0.94-0.99] & $3^{\circ}$ & $7^{\circ}$ \\
\hline
\end{tabular}

3

4

5 


\section{Table 7 (on next page)}

Intra-rater reliability analysis of goniometer and inertial sensor assessing wrist ROM. 


\section{Table 7.}

2 Intra-rater reliability analysis of goniometer and inertial sensor assessing wrist ROM.

\begin{tabular}{|c|c|c|c|c|c|c|c|c|}
\hline & \multicolumn{4}{|c|}{ Goniometer } & \multicolumn{4}{|c|}{ Sensor } \\
\hline & ICC & CI 95\% & SEM & $\mathrm{MDC}_{90}$ & ICC & CI 95\% & SEM & $\mathrm{MDC}_{90}$ \\
\hline \multicolumn{9}{|l|}{ Rater A } \\
\hline Flexion & 0.93 & [0.85-0.97] & $4^{\circ}$ & $9^{\circ}$ & 0.93 & [0.86-0.97] & $4^{\circ}$ & $9^{\circ}$ \\
\hline Extension & 0.84 & {$[0.65-0.92]$} & $5^{\circ}$ & $12^{\circ}$ & 0.82 & {$[0.62-0.92]$} & $5^{\circ}$ & $12^{\circ}$ \\
\hline Radial deviation & 0.81 & {$[0.60-0.91]$} & $4^{o}$ & $10^{\circ}$ & 0.83 & {$[0.63-0.92]$} & $4^{\circ}$ & $9^{\circ}$ \\
\hline Ulnar deviation & 0.85 & {$[0.67-0.93]$} & $4^{\circ}$ & $10^{\circ}$ & 0.87 & [0.72-0.94] & $4^{\circ}$ & $10^{\circ}$ \\
\hline \multicolumn{9}{|l|}{ Rater B } \\
\hline Flexion & 0.93 & [0.85-0.97] & $4^{\circ}$ & $10^{\circ}$ & 0.91 & {$[0.80-0.96]$} & $5^{\circ}$ & $11^{\circ}$ \\
\hline Extension & 0.89 & [0.76-0.95] & $4^{\circ}$ & $10^{\circ}$ & 0.89 & {$[0.76-0.95]$} & $4^{\circ}$ & $10^{\circ}$ \\
\hline Radial deviation & 0.88 & {$[0.75-0.94]$} & $3^{\circ}$ & $8^{\circ}$ & 0.88 & [0.74-0.94] & $3^{\circ}$ & $7^{\circ}$ \\
\hline Ulnar deviation & 0.81 & {$[0.58-0.91]$} & $5^{\circ}$ & $12^{\circ}$ & 0.81 & {$[0.59-0.91]$} & $5^{\circ}$ & $12^{\circ}$ \\
\hline
\end{tabular}

3 


\section{Table 8 (on next page)}

Inter-rater reliability analysis of goniometer and inertial sensor assessing wrist ROM. 


\section{Table 8.}

2 Inter-rater reliability analysis of goniometer and inertial sensor assessing wrist ROM.

\begin{tabular}{|c|c|c|c|c|c|c|c|c|}
\hline & \multicolumn{4}{|c|}{ Goniometer } & \multicolumn{4}{|c|}{ Sensor } \\
\hline & ICC & CI 95\% & SEM & $\mathbf{M D C}_{90}$ & ICC & CI 95\% & SEM & $\mathrm{MDC}_{90}$ \\
\hline \multicolumn{9}{|l|}{ 1st session } \\
\hline Flexion & 0.95 & [0.89-0.98] & $3^{\circ}$ & $8^{\circ}$ & 0.97 & [0.94-0.99] & $2^{\circ}$ & $6^{\circ}$ \\
\hline Extension & 0.92 & {$[0.80-0.96]$} & $4^{\circ}$ & $9^{\circ}$ & 0.93 & [0.86-0.97] & $3^{\circ}$ & $7^{\circ}$ \\
\hline Radial deviation & 0.92 & [0.83-0.96] & $2^{\circ}$ & $6^{\circ}$ & 0.96 & {$[0.92-0.98]$} & $2^{\circ}$ & $4^{\circ}$ \\
\hline Ulnar deviation & 0.92 & [0.84-0.96] & $3^{\circ}$ & $7^{\circ}$ & 0.95 & [0.90-0.98] & $3^{\circ}$ & $6^{\mathrm{o}}$ \\
\hline \multicolumn{9}{|l|}{ 2nd session } \\
\hline Flexion & 0.97 & [0.93-0.98] & $3^{\circ}$ & $7^{\circ}$ & 0.99 & [0.98-0.99] & $1^{\mathrm{o}}$ & $3^{\circ}$ \\
\hline Extension & 0.94 & [0.85-0.97] & $4^{o}$ & $8^{\circ}$ & 0.97 & [0.93-0.98] & $2^{o}$ & $5^{\circ}$ \\
\hline Radial deviation & 0.97 & [0.90-0.99] & $2^{o}$ & $4^{\circ}$ & 0.97 & [0.94-0.99] & $2^{o}$ & $4^{\circ}$ \\
\hline Ulnar deviation & 0.95 & [0.90-0.98] & $2^{o}$ & $6^{\circ}$ & 0.96 & [0.91-0.98] & $2^{o}$ & $6^{\circ}$ \\
\hline
\end{tabular}

3 
Figure 1

Werium $^{\mathrm{TM}}$ inertial sensor.

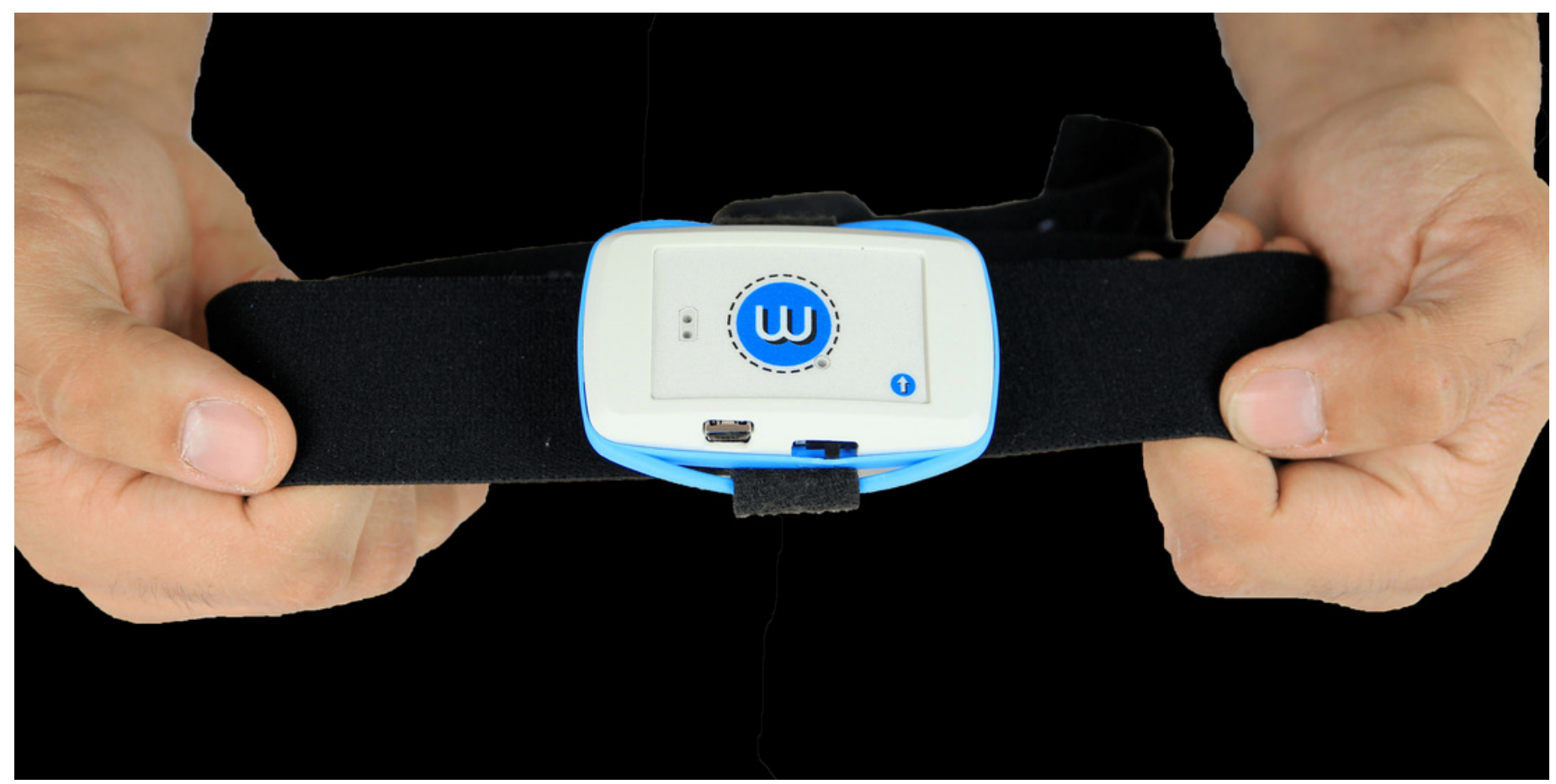


Figure 2

Screen of the software Pro Motion Capture ${ }^{T M}$ during a wrist asessment.

Virtual human models display real-time movements while equivalent ROM values are simultaneously reflected in (A) sagittal, (B) transverse and (C) frontal planes.

IN Werium

(w) werium

$\mathbf{A}$

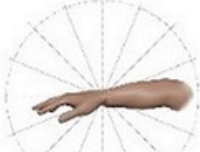

$0^{\circ}$

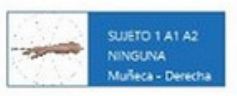

B
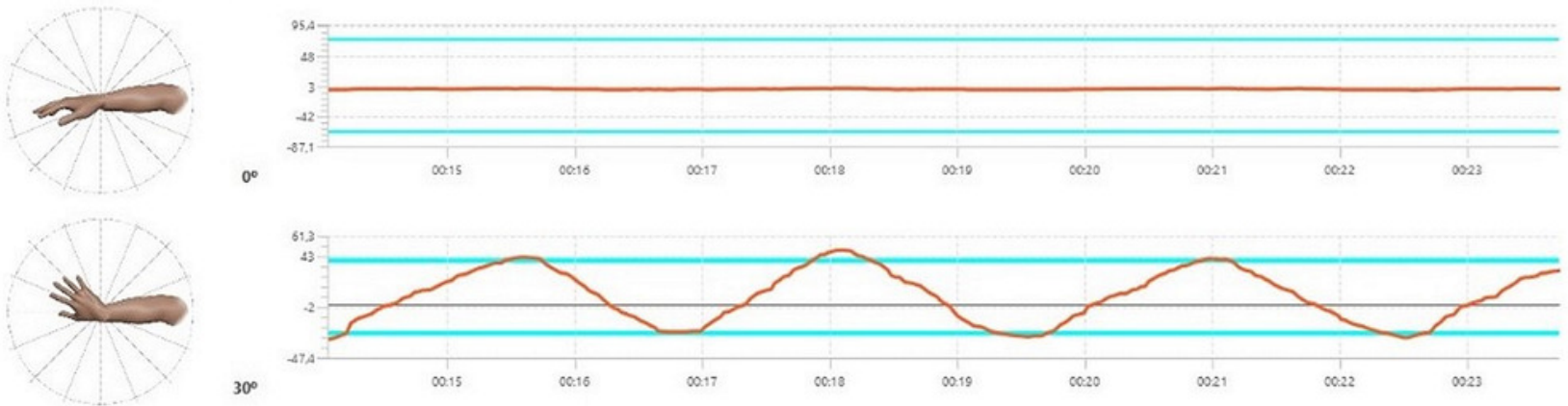

C

$30^{\circ}$
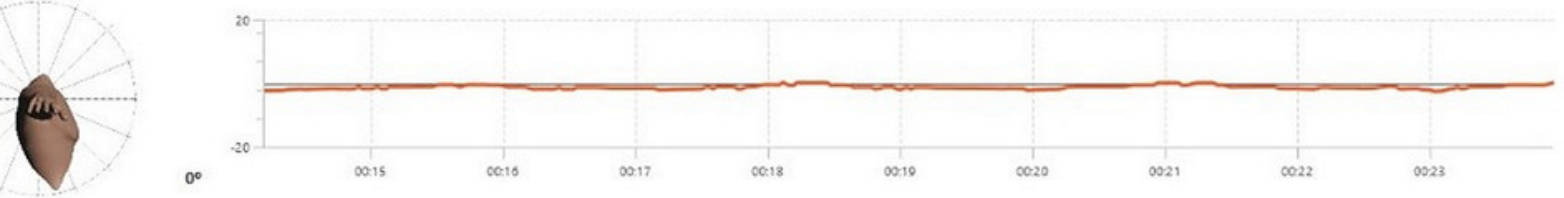

$0^{\circ}$ 


\section{Figure 3}

Anatomical landmarks for goniometer alignment before measuring of elbow and wrist.

(A) Bony landmarks on the longitudinal axis of the humerus, the forearm (radius) and the lateral epicondyle. (B) Bony landmarks on the ulnar styloid and the lateral midline of the fifth metacarpal. (C) Bony landmarks on the Capitate and the third metacarpal.

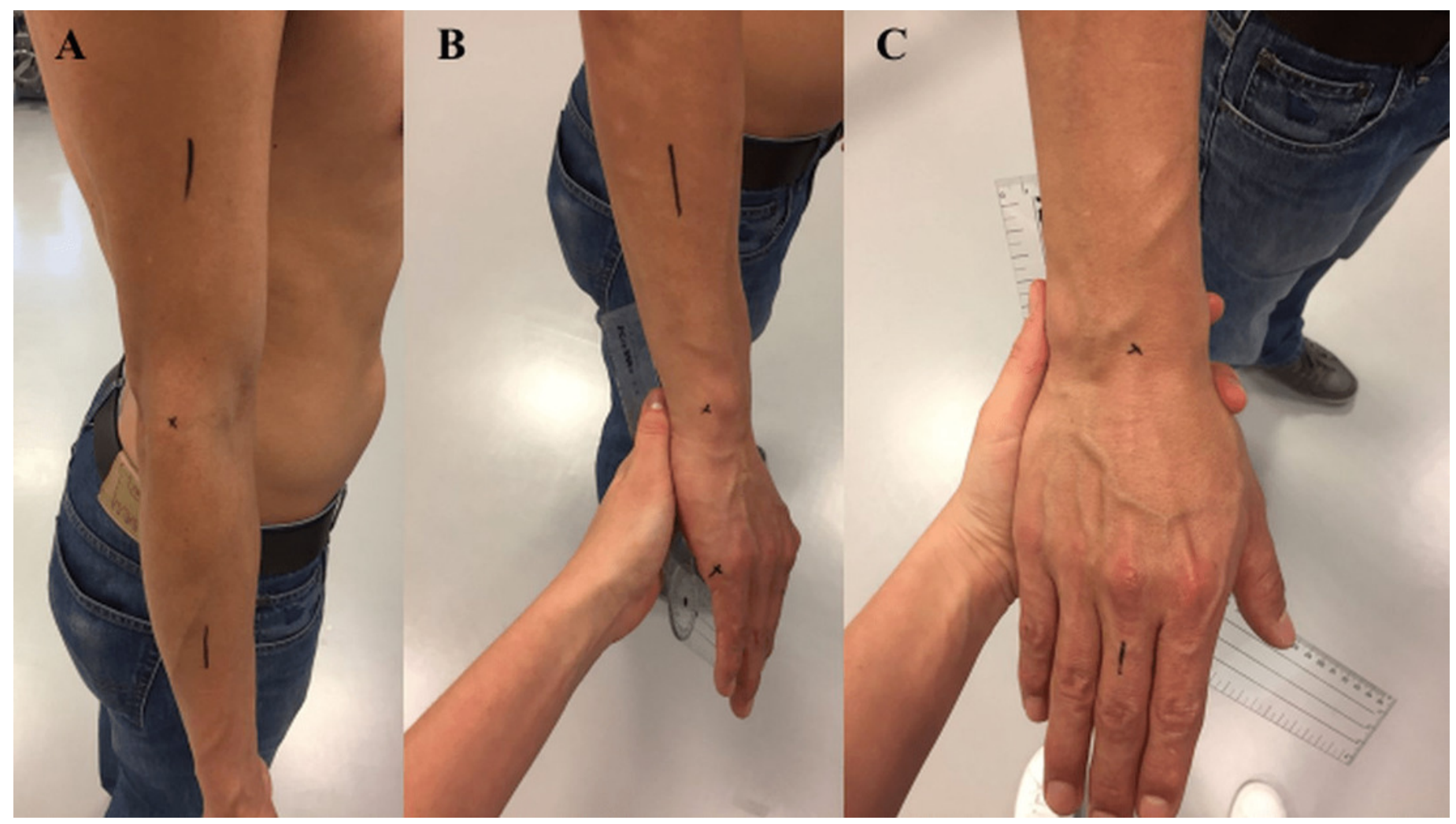




\section{Figure 4}

Measurement of elbow flexion ROM using the goniometer and inertial sensors.

(A) Starting position for flexion-extension ROM assessment. (B) Measuring of maximum flexion ROM. (C) Starting position for prono-supination ROM assessment. (D) Measuring of maximum pronation ROM (E). Measuring of maximum supination ROM.

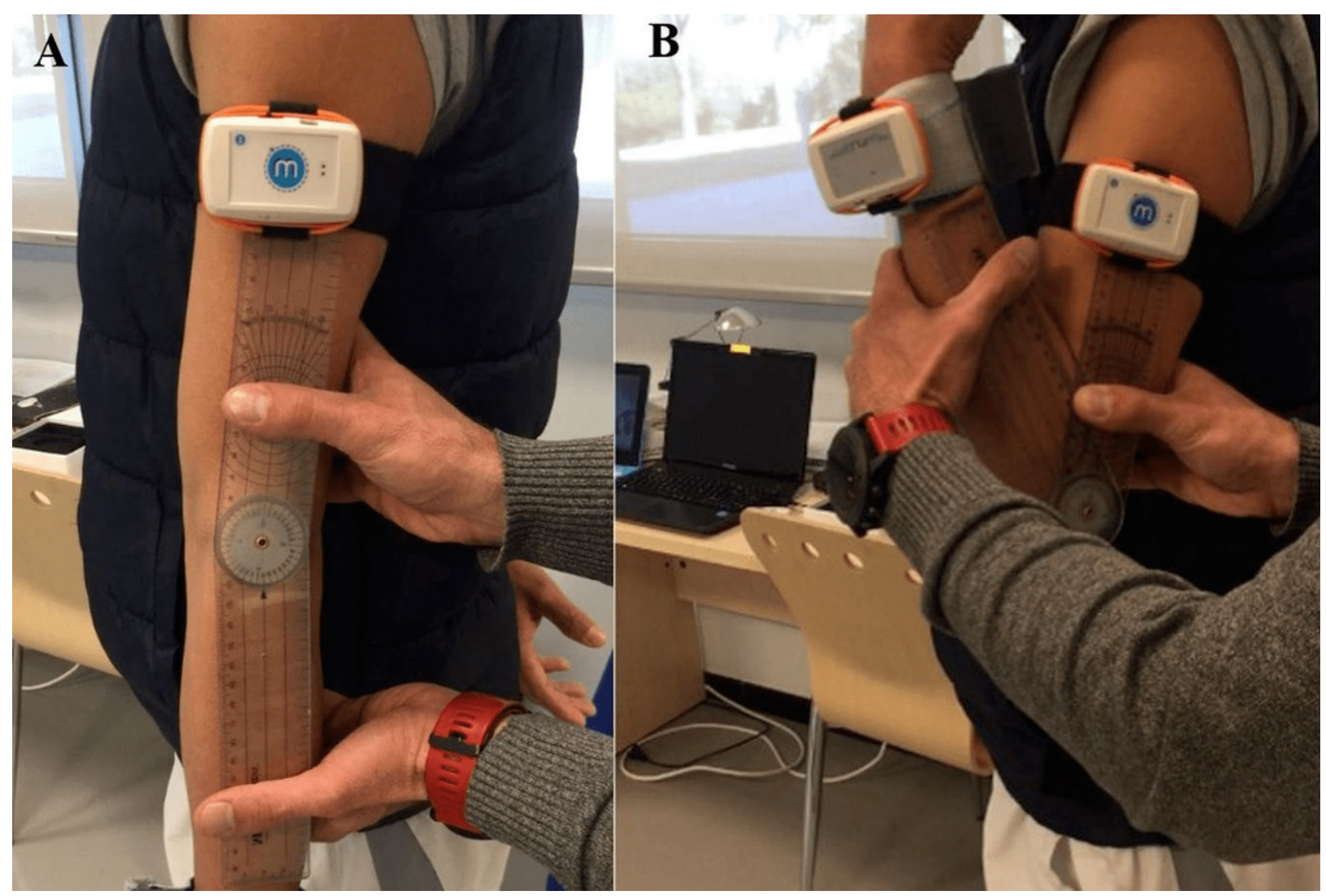




\section{Figure 5}

Measurement of elbow prono-supination ROM using the goniometer and inertial sensors.

(A) Starting position for prono-supination ROM assessment. (B) Measuring of maximum pronation ROM. (C) Measuring of maximum supination ROM.

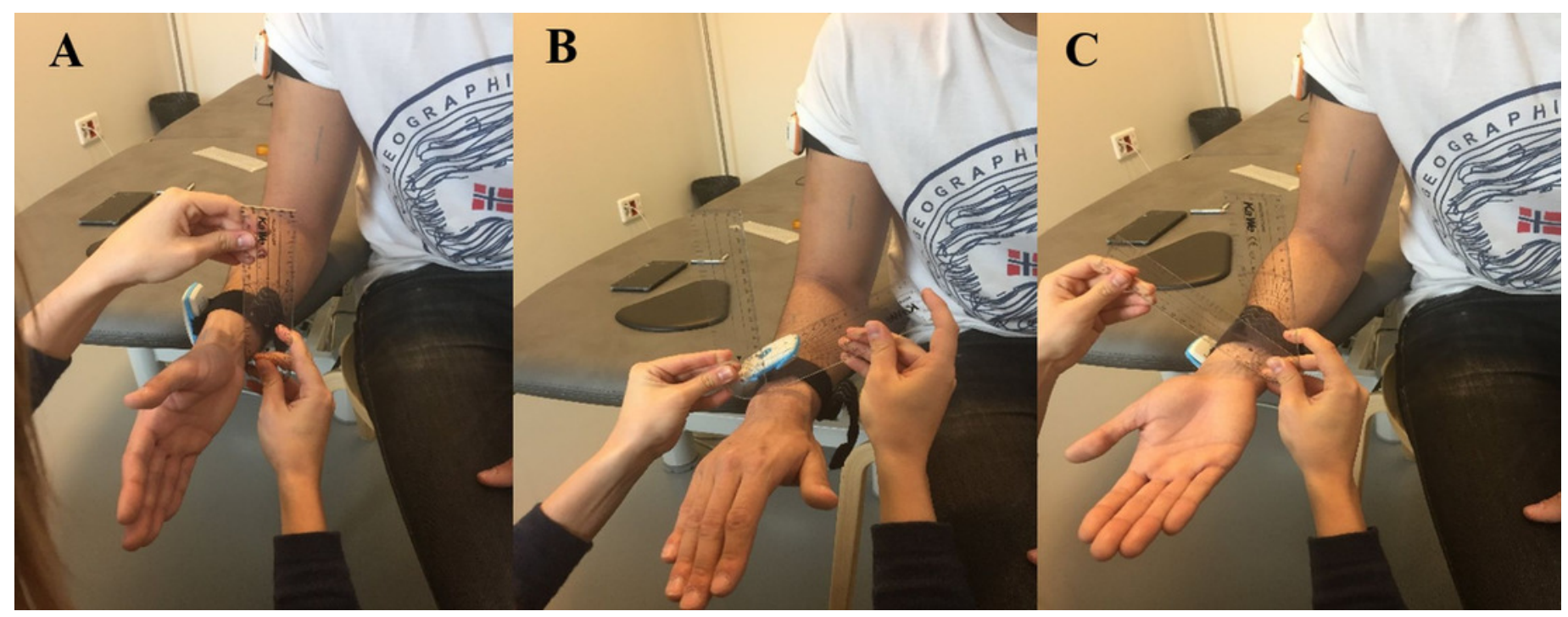




\section{Figure 6}

Measurement of wrist ROM using the goniometer and inertial sensors.

(A) Starting position for flexion-extension ROM assessment. (B) Measuring of maximum flexion ROM. (C) Measuring of maximum extension ROM. (D) Starting position for ulnardeviation ROM assessment. (E) Measuring of maximum radial deviation ROM. (F) Measuring of maximum ulnar deviation ROM.

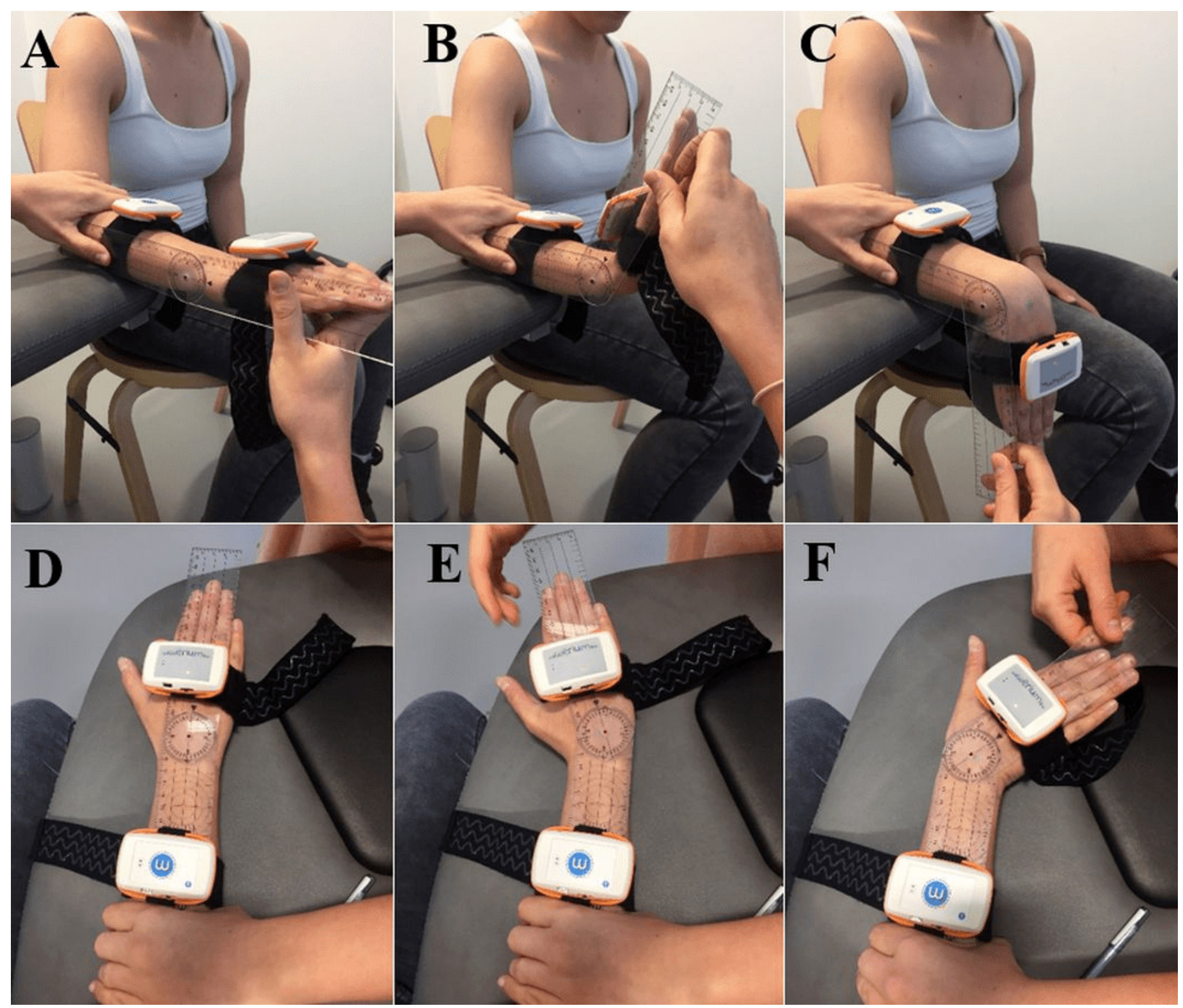




\section{Figure 7}

Bland-Altman plots for both instruments in elbow assessment.

The figure shows the dispersion graphs comparing the goniometer and inertial sensors for $(A)$ elbow flexion, (B) elbow supination and (C) elbow pronation. The means of both instruments are presented on the $\mathrm{X}$ axis, while the difference between them is presented on the $\mathrm{Y}$ axis. It can be noted that the majority of the values represented are distributed within the limits of agreement.
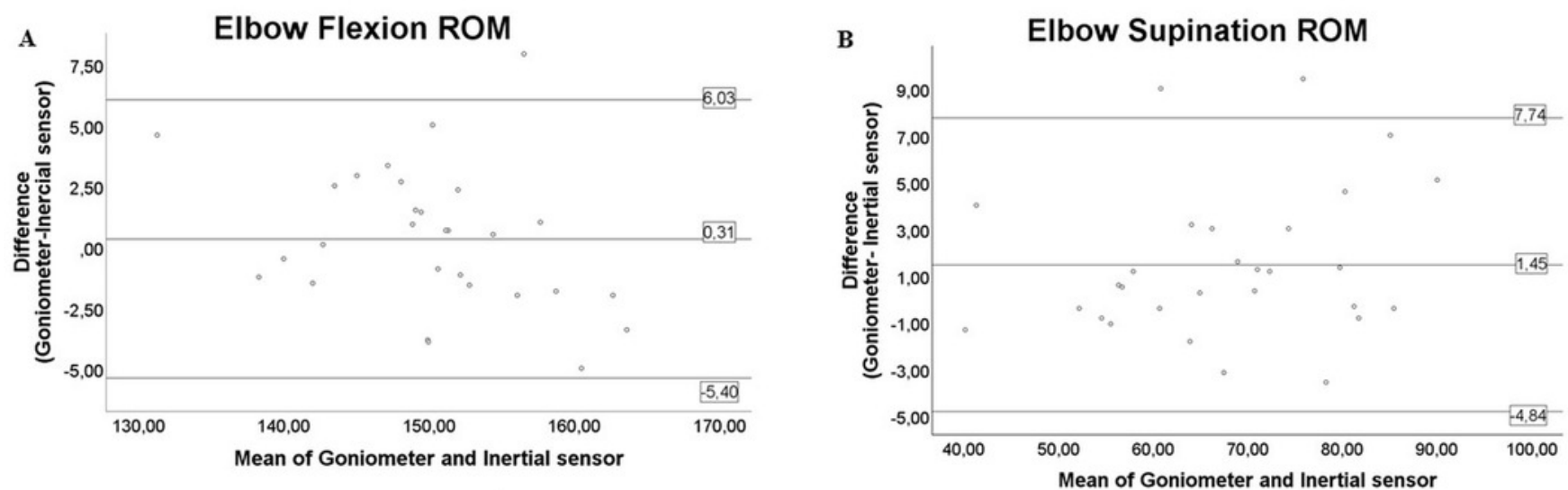

C

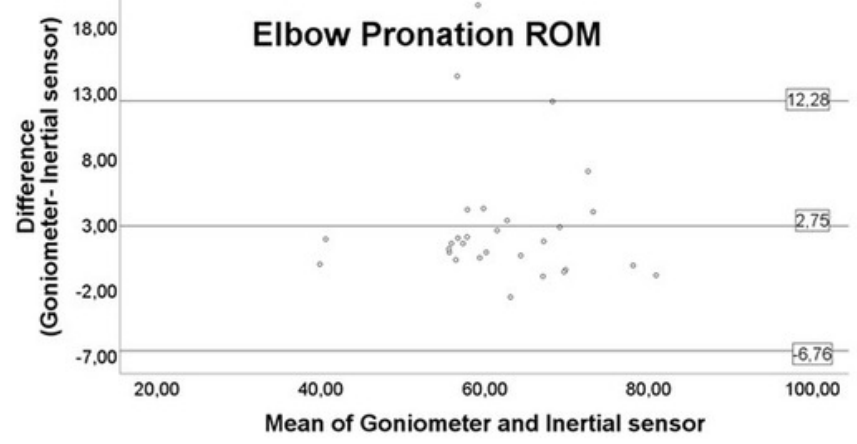




\section{Figure 8}

Bland-Altman plots for both instruments in wrist assessment.

The figure shows the dispersion graphs comparing the goniometer and inertial sensors for (A) wrist flexion, (B) wrist extension, (C) wrist radial deviation and (D) wrist ulnar deviation. The means of both instruments are presented on the $X$ axis, while the difference between them is presented on the $\mathrm{Y}$ axis. It can be noted that the majority of the values represented are distributed within the limits of agreement.

A

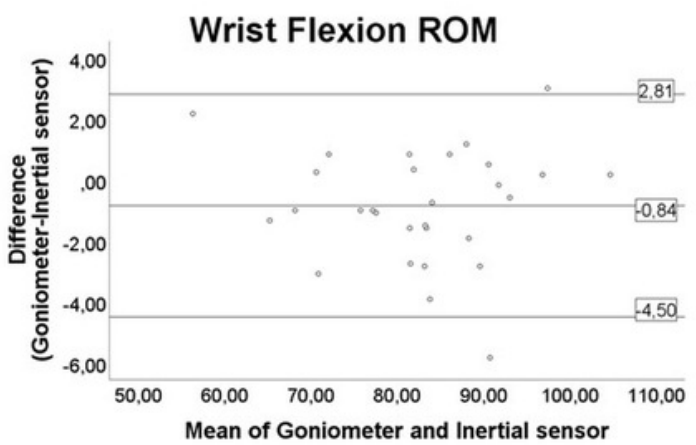

C

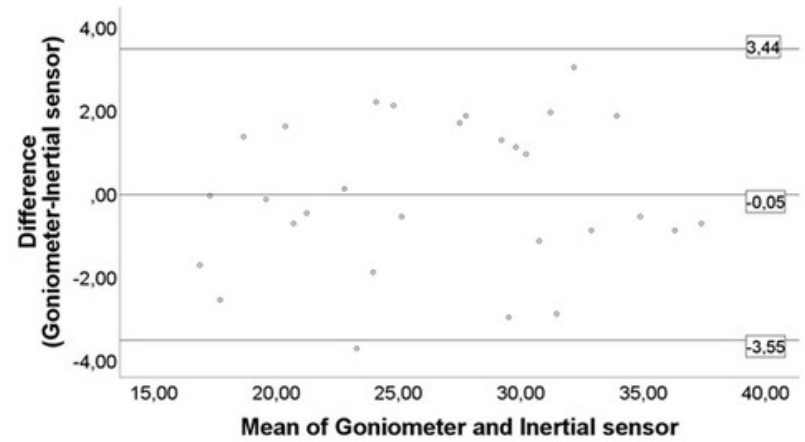

B

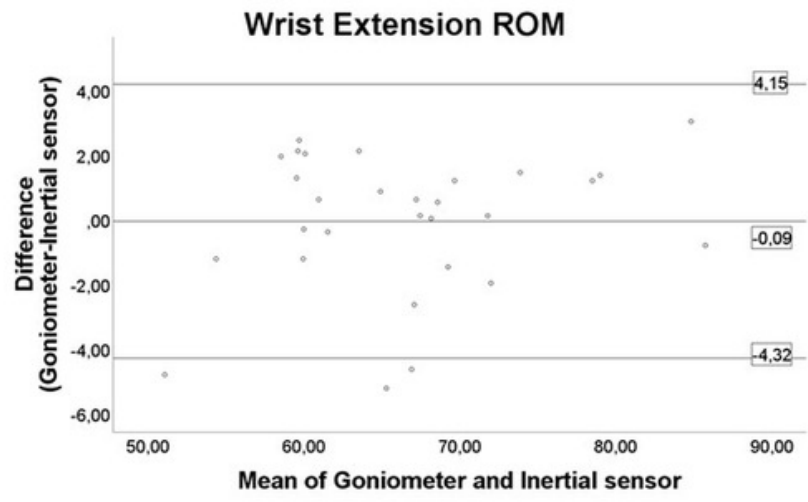

D

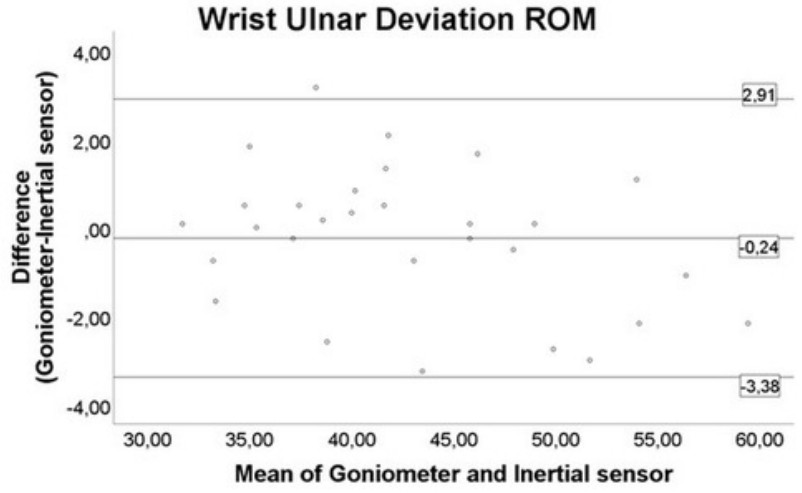

